NEWS

\title{
Pakistan's universities take up protest
}

Scientists and students in Pakistan have joined countrywide protests against the state of emergency, the suspension of the country's constitution and the sacking of its judiciary announced by the president, General Pervez Musharraf, on 3 November.

Thousands of staff and students are continuing to demonstrate at some of the country's top universities, among them the University of the Punjab, Lahore University of Management Sciences and the GIK Institute of Engineering Sciences and Technology in Topi.

There are also daily protests at the country's flagship Quaid-i-Azam University in Islamabad. On Tuesday, police tried to arrest some 500 protesting students and faculty at the university. But, according to news reports, vice-chancellor Qasim Jan stepped in and insisted that the protest continued.

This is the first time the scientific community has opposed military rule in such large numbers, says Pervez Hoodbhoy, chair of physics at Quaid-i-Azam University. "This is an unexpectedly big number, because for 20 years, since student unions were banned by General Muhammad Zia-ul-Haq [the last military ruler], Pakistani universities have been quite indifferent to national politics."

Since taking power in a coup in 1999 , General Musharraf has assumed the twin roles of head of state and head of the army. But he has also carved a reputation as an economic and social

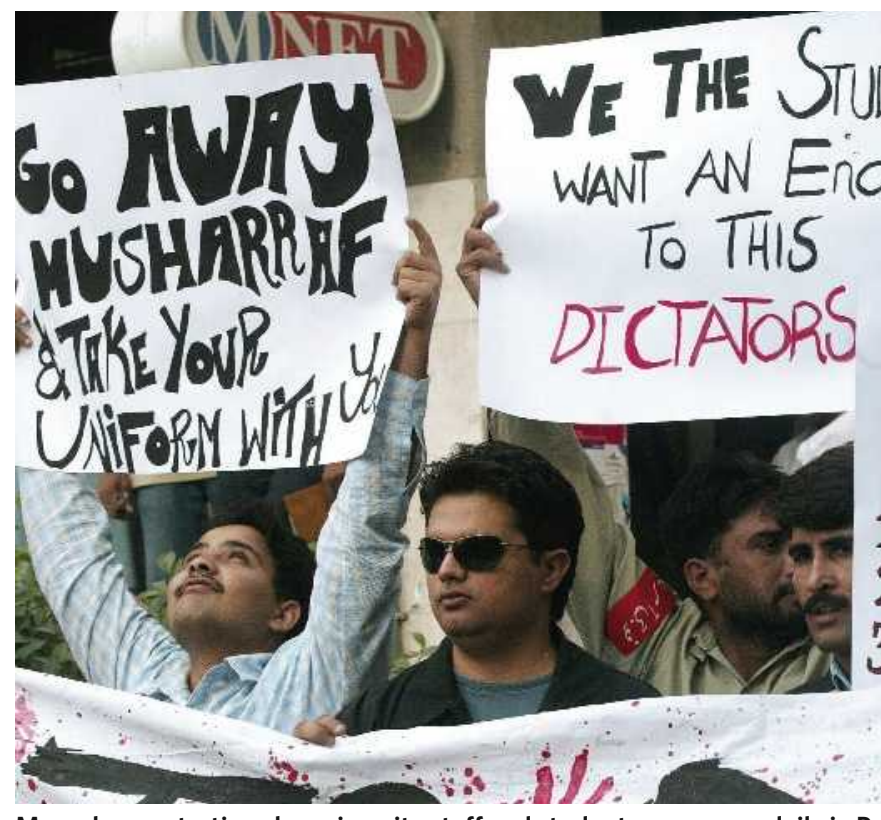

Mass demonstrations by university staff and students now occur daily in Pakistan.

liberal, and a bulwark against the al-Qaeda terrorist network. He has allowed independent media organizations to publish and broadcast. And Internet access has expanded from 40 cities in 1999 to 2,000 in 2006, with one in two Pakistanis having a mobile phone.

Musharraf also presided over a massive university building programme, and introduced a tenure-track system for university professors. The numbers of PhDs emerging from universities has more than doubled to 700 annually, with plans for a further doubling in the next four years.

But like all of Pakistan's previous military dictators (Musharraf is the fourth), he is having trouble letting go of the reins of power. With

\section{Merck settles Vioxx lawsuits for $\$ 4.85$ billion}

Three years after it pulled its blockbuster painkiller Vioxx from the market, Merck has agreed to pay $\$ 4.85$ billion to settle nearly 27,000 lawsuits that claim the arthritis drug caused heart attacks and strokes.

The settlement, although specifying that Merck "does not admit causation or fault", is in effect the legal expression of an admission by the company of a medical problem when it withdrew the \$2.5-billion-a-year drug in September 2004 after five years on the market. It was prompted to do so when patients taking Vioxx in a Mercksponsored clinical trial showed a doubled risk of heart attack and stroke (R. Bresalier et al. N. Engl. J. Med.352, 1092-1102; 2005). At the time, the company promised to fight in court every lawsuit brought against it.
The settlement agreed on 9 November is a qualified positive for Merck. The New Jersey company's Vioxx liability was initially pegged by Wall Street at tens of billions of dollars. What's more, the deal will go ahead if only $85 \%$ of eligible claimants agree to it, lowering the risk that thousands of cases will continue to drag on in court.

Both sides claim victory.

"Merck does not admit

Plaintiffs' attorney Mark

Lanier of the Lanier Law Firm

in Houston, Texas, applauded

the deal as "a huge opportunity for those who have been hurt by the drug to receive a fair settlement" and said he would counsel the 1,006 plaintiffs he represents to accept it.

Bruce Kuhlik, Merck's general counsel, called the settlement "a product of the success that we've had in the litigation so far".
Despite a stunning \$253-million judgment against Merck in the first Vioxx trial (see Nature 436, 1070; 2005) - later reduced to around \$26 million under Texas damage law - Merck has won 11 Vioxx cases so far, whereas plaintiffs have prevailed in only 5 .

Those numbers reflect the difficulty of proving causation in individual cases, regardless of the soundness of aggregate findings from large randomized clinical trials, when a drug's adverse effects - and the risk factors that can lead to them - are broadly and independently prevalent in the population. That helped defence lawyers persuade juries that Vioxx wasn't at fault in the heart attacks suffered by plaintiffs such as Elaine Doherty, an overweight 68-yearold with diabetes and high blood pressure.

"What was so clever about the defence 
elections set for January, some analysts are predicting that he may agree to a power-sharing alliance with opposition leader Benazir Bhutto in which he remains head of state but gives up his role as head of the army, with Bhutto assuming the role of prime minister (for the third time).

Such a scenario could have uncertain consequences for science and education. Bhutto's previous stint as prime minister (1993-96) was characterized by low investment in research and higher education. She was also much criticized by the scientific community for failing to appoint a minister for

"For 20 years, science.

Pakistani

Leaders of Pakistan's universities have been quite scientific community are meeting this week at the Academy of Sciences for the Developindifferent to ing World in Trieste, national politics." Italy, for a seminar originally designed to showcase the country's progress in science, technology and higher education. Much of the meeting is now likely to be devoted to speculation on what will happen after the election.

Among the speakers will be Atta-ur-Rahman, chair of Pakistan's Higher Education Commission and a professor of chemistry at the University of Karachi. He told Nature that an incoming government had a responsibility not to throw away the past: "I hope the new government will continue on the present path. We have made huge advances in the past several years and it would be a great shame if this were lost." Ehsan Masood

strategy is that they argued it at the individual level. It certainly drove down the estimates of how much this was going to cost them," says Garret FitzGerald, chair of pharmacology at the University of Pennsylvania in Philadelphia, whose mechanistic studies in humans and mice first pointed to the cardiovascular risks of Vioxx and other drugs in its class.

The Vioxx cases are in stark contrast to the lawsuits brought by people who took Fen-Phen, a popular diet-drug combination withdrawn in 1997 . The signature, and relatively uncommon, heart-valve damage caused in those cases left drug-maker Wyeth liable for damages of more than $\$ 21$ billion.

Indeed, for scientists and clinicians, the main message of the settlement may be that reliable, personalized lawsuit victories remain as elusive as personalized medicine itself, and for many similar reasons.

Meredith Wadman

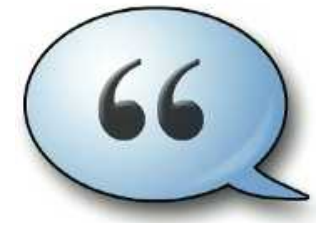

HAVE YOUR SAY

Comment on any of our news stories, online.

www.nature.com/news

\section{HIV vaccine may raise risk}

An HIV vaccine made by Merck that failed in clinical trials may have increased the susceptibility of some trial participants to the AIDS virus, researchers reported last week. The findings have left scientists grappling with the problem of how to handle future trials of vaccines that use similar strategies to stimulate an immune response.

The trial was suspended in September, when preliminary analyses showed that the vaccine failed to protect participants against HIV (see Nature 449, 390; 2007). The vaccine consisted of three HIV genes carried by a weakened viral vector. Neither the HIV genes nor the vector, made from a common-cold virus called adenovirus 5, were capable of causing infection.

But it seems that trial participants who had a pre-existing immunity to adenovirus 5 were more likely to become HIV-positive if they received the vaccine. Among male volunteers who had high levels of antibodies against the adenovirus, 21 of 392 became infected in the vaccinated group, but only 9 of 386 were infected in the placebo group. The vaccine did not affect infection rates in men with no adenovirus- 5 immunity.
The trial was not designed to examine the relationship between adenovirus -5 immunity and HIV infection, and researchers cannot say whether the result is statistically significant. But they can't ignore the findings, says Anthony Fauci, director of the National Institute of Allergy and Infectious Diseases in Bethesda, Maryland. The start of another HIV-vaccine trial has been pushed back several months to allow more time for scientific review, he says.

For now, researchers are trying to determine whether the vector is to blame or whether those with high adenovirus-5 immunity are at risk for unrelated reasons. Immunologists say it is also theoretically possible that vaccination in those with preexisting immunity may have triggered an immune response that transiently boosted production of activated CD4 cells - the very immune cells that HIV infects.

That theory leaves several questions unanswered. For example, it is not known how long after vaccination the activated CD4 cells would have remained in the mucosal surfaces where HIV first gains entry, says Fauci.

Researchers are nevertheless concerned. One possible solution is to limit future trials of adenovirus-5-based vaccines to participants with very low levels of immunity to the vector, says Gary Nabel, director of the Vaccine Research Center at the National Institutes of Health in Bethesda, Maryland. But doing so would close off the trials to a large proportion of the population they aim one day to help: more than $80 \%$ of sub-Saharan Africans have significant levels of adenovirus- 5 immunity. In addition to the planned HIVvaccine trial, an Ebola vaccine in development also relies on an adenovirus -5 vector.

But at this stage in vaccine development, researchers are just looking for a proof of concept rather than a vaccine that can be put directly to use, says Lawrence Corey, lead investigator of the HIV Vaccine Trials Network. Alternatives to adenovirus 5 are being developed, and may be substituted once the efficacy of a vaccination strategy has been shown. Nevertheless, vaccine developers will face challenging decisions in light of the new data, he says: "Translating uncertain data into policy is always a difficult issue."

Heidi Ledford

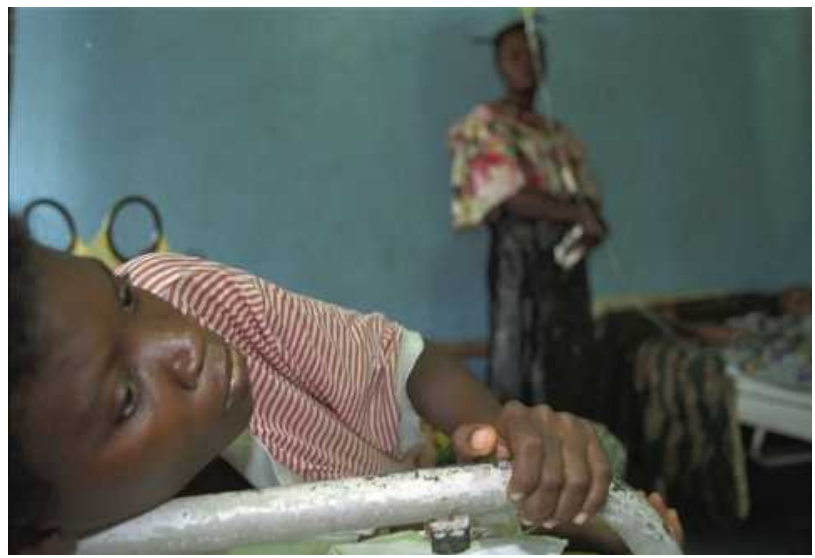

Hopes for a future vaccine against the devastating Ebola virus may have been set back by the results of a clinical trial of an HIV vaccine. 